\title{
EFFICIENCY AND REGULATION OF THE SLOVENIAN ELECTRICITY DISTRIBUTION COMPANIES
}

\author{
Prof. Dr. Massimo Filippini \\ CEPE - Centre for Energy Policy and Economics, Federal Institute of Technology, Zurich, \\ and Department of Economics, Università della Svizzera Italiana, Switzerland.
}

Prof. Dr. Nevenka Hrovatin

University of Ljubljana, Faculty of Economics, Kardeljeva plošcad 17, 1000 Ljubljana, Slovenia

Tel.: (386) 15892450

Fax: (386) 15892698

E-mail: nevenka.hrovatin@uni-1j.si

Jelena Zoric

University of Ljubljana, Faculty of Economics, Slovenia

\begin{abstract}
The Slovenian Energy Law, adopted in 1999, has opened the internal market to competition up to $64 \%$ of the final consumption. The opening of the internal market to foreign competition is envisaged for 2003. With regard to the methodology of price regulation, the Energy Law introduces the "price-cap" regulation, which aims to give firms incentive for cost reduction. To provide information for effective price regulation, we estimated a cost frontier function on a sample of Slovenian electricity distribution utilities over the 1991-2000 period. The estimated efficient frontier could be used by Slovenian regulatory agency as a benchmark to regulate network access prices. Our results show that Slovenian distribution companies are cost inefficient. We have also proved the presence of increasing returns to scale with most utilities not achieving the minimum efficient scale. Thus, the Slovenian regulatory authority should consider how to induce mergers of small electricity distribution utilities into larger units.
\end{abstract}

Keywords : regulation, stochastic frontier cost function, Slovenian electricity distribution companies 


\title{
EFFICIENCY AND REGULATION OF THE SLOVENIAN ELECTRICITY DISTRIBUTION COMPANIES
}

\author{
Prof. Dr. Massimo Filippini \\ CEPE - Centre for Energy Policy and Economics, Federal Institute of Technology, Zurich, \\ and Department of Economics, Università della Svizzera Italiana, Switzerland.
}

Prof. Dr. Nevenka Hrovatin

University of Ljubljana, Faculty of Economics, Kardeljeva plošcad 17, 1000 Ljubljana, Slovenia

Tel.: (386) 15892450

Fax: (386) 15892698

E-mail: nevenka.hrovatin@uni-1j.si

Jelena Zoric

University of Ljubljana, Faculty of Economics, Slovenia

\section{Introduction}

As an associate member of the European Union, Slovenia cannot ignore the EU's Electricity Directive which has dictated significant changes in the directions of liberalisation, increased efficiency and competitiveness on a global scale. In order to comply with the Electricity Directive, in 1999 Slovenia adopted the Energy Law, which is set to significantly change the way its utilities operate.

Like the majority of electric power reforms, Slovenia's reform also focuses on the introduction of a price mechanism and competition in generation and supply, whereas transmission and distribution activities remain regulated activities due to their natural monopoly character. Thus, deregulation of the power sector is combined with a (re-) regulation of electricity network prices. In this respect, the regulatory authorities have adopted a variety of approaches to regulate distribution prices. The most widely adopted schemes are based on price cap, revenue cap, and yardstick regulation models. ${ }^{1}$ However, in practice, most regulatory schemes use a combination of these different incentive regulation models. ${ }^{2}$ 
Usually, these incentive-based regulatory models make use of information obtained from a benchmarking of the utilities' costs. Within this framework, one of the most interesting benchmarking approaches is based on the econometric estimation of a frontier cost function for a sample of firms. The efficient frontier is then used as a benchmark against which the relative performance of a single firm is measured. In this paper, we analyse the cost structure of Slovenian electricity distribution network operators with respect to the cost- and scaleefficiency of the industry. The Slovenian authorities might use our results obtained from the estimated frontier cost model to regulate prices for accessing distribution networks.

The paper is organised as follows. After a brief overview of the current industrial structure of Slovenia's electricity sector in the first part of this paper, we present the legislative changes and indicate possible impacts of the opening the market for Slovenian electricity utilities. Further, the Energy Law introduces price-cap regulation in distribution activities which aims to give firms an incentive to undertake efficient production. For this reason, a special emphasis is also placed on the regulation of network access prices at the distribution level in order to allow non-discriminatory access to utilities' transmission and distribution lines. In the second part of the paper, we present the econometric results of the estimation of a stochastic frontier cost function which could be used to increase the informational basis for more effective price-cap regulation. In addition, we try to establish the presence of economies of scale and the potential inefficiencies of individual electricity distribution utilities.

\section{Slovenian electricity sector}

\section{Structure of the Slovenian electricity industry}

The structure of Slovenia's electricity sector can be considered as a horizontally and vertically disintegrated one (the pictorial representation can be found in Figure 1). Before the opening of the electricity market in 2001, there were eight publicly-owned independent companies in generation: the nuclear power plant (NPP Krško $)^{3}$, three hydropower companies (Drava RC (River Company), Soca RC and Sava RC), two thermal power plants (the Šoštanj lignite-fired power plant (TPP Šoštanj) and the Trbovlje coal-fired power plant (TPP Trbovlje)), Ljubljana's coal-fired co-generation plant (TE-TOL) and oil and gas power plant Brestanica, which provides 
reserve capacity (Hrovatin, 1999). In the beginning of 2001, all public companies except the NPP Krško, the TTP Trbovlje and the TE-TOL merged into one generating public holding company Slovenske elektrarne (HSE). In 2001, the nuclear power plant generated 39\% of power in Slovenia, hydropower companies generated $27 \%$, and the others $34 \%$ (mostly thermal power plants including the co-generation plant Ljubljana and Brestanica). ${ }^{4}$

With annual electricity generation of $12.900 \mathrm{GWh}$, the Slovenian electricity system is one of the smallest in Europe, only bigger than Iceland and Luxembourg. Generation costs of Slovenia's electricity system are high compared to the EU average. These high costs are mostly caused by coal-fired power plants, while nuclear power costs are comparable to those of Germany and Japan. Operations of small, old and inefficient units and the relatively high prices of domestic coal push system costs upwards. Competition between existing units is impossible due to cost differentials originating from different generation technologies. In 1999, average costs ranged from SIT $4.66(€$ 0.02408) for Drava RC to SIT 19.73 (€ 0.10190) per kWh for TTP Trbovlje (Hrovatin, 2001a). In contrast to many other European countries where excess capacities with the highest cost should be eliminated through competition, there is a lack of electricity supply in Slovenia. Until liberalisation also encompasses purchases from abroad, the supply of even the most expensive unit will be required to satisfy demand.

Transmission and distribution have retained their natural monopoly characteristics due to economies of scale. The transmission company ELES is responsible for the dispatch and transmission of electricity to five regional distribution companies majority owned by the state (Elektro Ljubljana, Elektro Maribor, Elektro Celje, Elektro Primorska and Elektro Gorenjska). Prior to market opening, distribution companies operated as local monopolies within their region. Four groups of final customers, customers on high voltage $110 \mathrm{kV}$, customers on high voltage $34 \mathrm{kV}$, households and the remaining group on low voltage $0.4 \mathrm{kV}$ purchased electricity directly from the respective distribution company licensed to supply electricity in their own region. After 15 April 2001, distribution companies retained their monopolistic position towards non-eligible customers, while eligible customers can freely choose their suppliers. In addition, five large industrial customers (four steel producers and one aluminium company), which account for around 20 percent of total domestic demand, were buying electricity directly from the transmission company ELES until the effective implementation of their eligible customers' rights for purchases in the domestic market at the beginning of 2002. 
Before the market's opening, power plants were utilised on an integrated basis in accordance with a daily dispatch plan prepared by the transmission company ELES. ${ }^{5}$ Electricity was sold on the basis of short-term agreements between generators, the transmission company and distribution companies. Sales revenues were distributed on the basis of administratively determined costs of each generation unit, thus resulting in considerable cross-subsidisation. The inexpensive Drava RC subsidised the expensive coal-fired plants, which in turn contributed to maintaining lower electricity prices for final customers. The government controlled the prices paid by final customers. Prices were uniform for each customer group, irrespective of their geographical location.

Over the past few years, the electricity industry has been struggling to adjust its prices to full-cost level. In the Strategy for Economic Development (Potocnik et al., 1995), Slovenia committed itself to adjusting electricity prices to the European Union average through annual $7 \%$ increases. While households' prices were still $16 \%$ below the EU average in 1999, prices for industrial customers were quite high, $6 \%$ above the EU average with industries calling for their reduction (Hrovatin, 2001a). In 2001, average prices for households were around 22\% below the EU average and for industry about 10\% below (Ministry for the Environment and Spatial Planning, internal data, 2002).

\section{New Energy Law and opening of the electricity market}

The key principle of the EU's Electricity Directive (96/92/EC) is the gradual and progressive opening up of the market which should lead to an increase in economic efficiency and increased competitiveness on a global scale. As a candidate country for entering the EU, in 1999 Slovenia adopted the Energy Law which follows the Electricity Directive and is set to significantly change the way its utilities operate. From the two options offered by the Electricity Directive for access to the system namely, Single Buyer and Third Party Access (TPA), Slovenia has chosen a regulated TPA. According to the new Energy Law, the electricity market is being introduced in two stages. In the first stage, running from 15 April 2001 until 2003, the market was opened to domestic purchases. In the second stage, starting at the beginning of 2003, foreign companies may participate in the market while eligible customers will also be entitled to import electricity under commercial agreements. 
Figure 1

Structure of the Slovenian electricity industry in $2001^{1)}$

$\begin{array}{lllllllllll}\text { P } & \text { R } & \text { O } & \text { D } & \text { U } & \text { C } & \text { T } & \text { I } & \text { O } & \text { N } & (12.901 \text { GWh })^{2)}\end{array}$

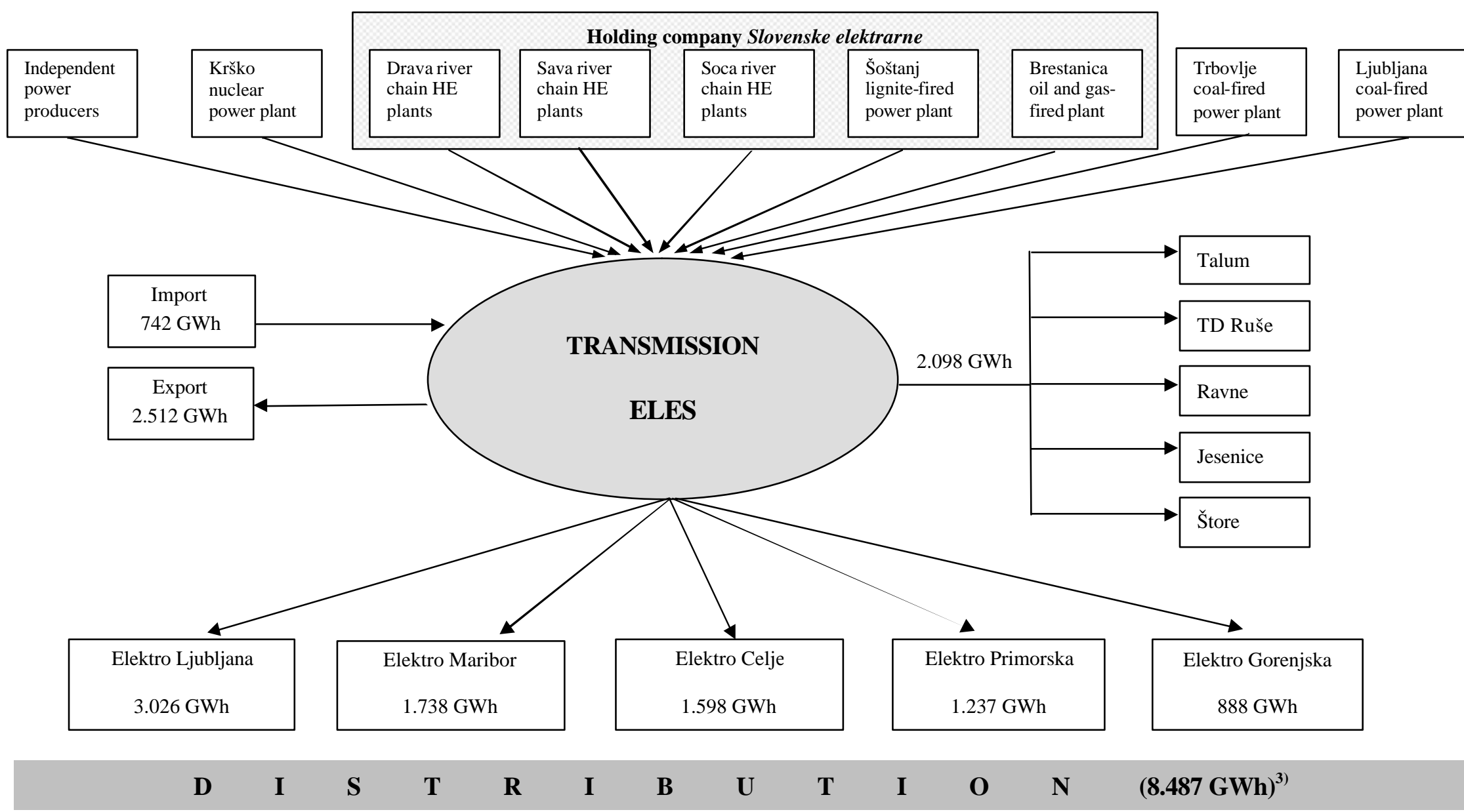

Source: Hrovatin (1999), modified 
Notes to Figure 1:

1) Numbers beneath indicate the annual output/s ale in GWh in 2001 (source: Annual Report of ELES in 2001, Annual Reports of the Slovenian electricity distribution companies in 2001).

2) In 2001, the nuclear power plant generated $39 \%$ of power in Slovenia, hydropower companies $27 \%$ and thermal power plants $34 \%$.

3) From 15 April 2001, five distribution companies sell electricity to two final customer groups: eligible and non-eligible customers. According to the voltage level, customers are further classified into four customer groups. 
In Slovenia, the threshold for defining eligible customers has been set relatively low. All customers with a connected capacity of more than $41 \mathrm{~kW}$ at one location will have the right to buy electricity freely. This amounts to around $64 \%$ of final consumption. Most companies in the manufacturing sector and services became eligible customers. Mainly households and some low-voltage customers have to purchase electricity directly from distribution companies.

The new institutional settings will require a different division of operations among players in the market. The transmission company ELES will continue to manage its transmission tasks and will act as the "pool" market organiser through its subsidiary Borzen. In addition, it will seek out new opportunities for diversification, particularly by spreading its activities into the telecommunications industry. Distribution companies will partly maintain their monopolistic position in relation to non-eligible customers. They will also continue to manage, operate and maintain the distribution network and distribute electricity through their grids. On the other hand, they will have to develop trading and marketing operations to be able to compete with newcomers to the market - electricity sellers. They will also have the opportunity to invest in new, lower-cost generation units.

Generation companies and eligible customers now have two options for selling and purchasing electricity: in the electricity market or through short-term and long-term contracts. Slovenia introduced an electricity market similar to the British pool before the latest modifications. In this market, scheduling and dispatch is based on a least-cost-merit order to meet demand. The system's marginal price reflects the cost of the most expensive generation unit that needs to be put into operation in order to satisfy demand. As elsewhere, it is reasonable to expect that the majority of purchases will be arranged contractually rather than through the market. In January 2002, when the pool was launched, only $14 \%$ of final electricity consumed was bought in the pool.

Generation companies soon realised that competition among them would reduce their bargaining power vis -àvis eligible customers and, hence, would be detrimental to their profits. In addition, many generation utilities would be faced with high stranded costs. As a result, the holding company Slovenske elektrarne (HSE) was established. At the beginning of 2002, when eligible customers had to sign new purchasing contracts, the increased bargaining power of the holding resulted in higher generation prices. In addition, to protect utilities with the highest costs (i.e. the TPP Trbovlje and the Ljubljana co-generation power plant), the government safeguarded their generation by the permissible $15 \%$ supply of primary resources under the EU's Electricity 
Directive and by measures protecting independent generators, respectively. Since opening the market without government intervention would initially significantly harm the performance of generators, these trends came as no surprise. ${ }^{6}$

\section{Regulation of the electricity industry}

For carrying out regulatory activities in the gas and electricity sector, an independent regulatory body, the Agency for Energy, has been established. Its main tasks will be to:

- issue licences;

- regulate network prices in transmission and distribution;

- resolve disputes resulting from the denial of access or pricing issues; and

- ensure transparent and non-discriminatory operations of the market.

It is worth mentioning that the transfer of pricing issues to the Agency will not include all aspects of electricity pricing. In the new system the government will continue to regulate prices for non-eligible customers, even though it would be better to delegate all pricing issues to the professional and independent Agency. Hence, there remains a potential threat that the existing method of price determination based on political considerations and other macroeconomic goals (e.g., reducing inflation) will continue.

As regards the methodology of price regulation, the Energy Law follows the incentive-based "price-cap" regulation, which has recently gained its popularity in EU member states as well (Hrovatin, 2001b). ${ }^{7}$ The initial revision of the price structure and price levels prior to the beginning of price-cap regulation (RPI-X regulation) is essential. ${ }^{8}$ A regulatory failure in Slovenia may at least be partly avoided by setting initial prices to reflect the costs prior to imposing the RPI-X regulation and setting $\mathrm{X}$. The final price should be determined as a combination of four components: generation cost plus transmission cost plus distribution cost plus supply cost, each component reflecting the full costs of the activity in the chain.

With the introduction of regulated TPA, the electricity distribution utilities are obliged to allow nondiscriminatory access to companies that wish to transmit electricity over the utility's transmission and distribution lines for sale to final customers. Since the distribution companies are local monopolies, regulation 
of network access prices by the Agency for Energy is necessary. Prices are to be determined separately for the transmission and distribution phase in a way that stimulates efficiency. The Agency is supposed to set a pricecap that will not be changed for a regulatory period, thus giving some incentive for efficient production and cost reduction. However, due to the imperfect information available to the regulator there are some problems with price-cap regulation since the regulator does not know a firm's true costs. High costs may be due to a firm's particular production situation or merely because of its inefficiency.

In setting the initial price level and the yearly efficiency factor $X$ in price-cap regulation, the regulator could use some form of benchmarking analysis on the costs of utilities. In this case, the benchmarking analysis is used to establish a larger informational basis for more effective price-cap regulation that reduces the informational asymmetries between firms and the regulator regarding costs. Following this idea, in the next part of the paper we estimate the cost function for electricity distribution companies in Slovenia and indicate a way in which the results may be employed by the regulatory agency.

\section{Cost frontier model for electricity distribution}

\section{The stochastic cost frontier model}

A frontier cost function identifies the minimum costs at a given output level, input price and existing production technology. It is unlikely that all firms will operate at the frontier. Failure to attain the cost frontier implies the existence of technical and allocative inefficiency. In this paper we consider the estimation of a stochastic frontier cost function using panel data. ${ }^{9}$ To illustrate this econometric approach, consider the cost function:

$C_{i t}=X_{i t} \beta+u_{i}+v_{i t} \quad u_{i} \geq 0 \quad i=1,2, \ldots, N$ and $t=1,2, \ldots, T$

In this specification the error term is composed of two parts: the first, $u_{i}$, is a one-sided non-negative disturbance reflecting the effect of costs; the second, $v_{i t}$, is a two-sided disturbance capturing the effect of noise. The statistical noise is assumed to follow a normal distribution, and the inefficiency term $u_{i}$ is generally assumed to follow either a half-normal or truncated normal distribution. ${ }^{10}$

In a stochastic frontier setting, efficiency is measured as the ratio of actual costs to the least-cost level: 


$$
E F F_{i}=\frac{E\left(C \mid u_{i}, X_{i}\right)}{E\left(\mathcal{d} u_{i}=0, X_{i}\right)}
$$

Therefore, predictions of cost efficiency $\left(E F F_{i}\right)$ are calculated according to the following expression:

$$
E F F_{i}=\frac{X_{i t} \beta+u_{i}}{X_{i t} \beta} \geq 1
$$

These predictions are made using the procedure suggested by Jondrow et al. (1982).

\section{Specification of the frontier cost function for electricity distribution utilities}

The costs of operating a distribution system are the costs of building and maintaining the system of service lines, mains and transformers, and of measuring and billing electricity. The most important factors affecting distribution costs are: the total number of customers served, the dispersion of consumers in the service area, the size of the distribution area, the total $\mathrm{kWh}$ sold, the ength of distribution line, the security of supply and maximum demand.

Electricity distribution utilities operate different networks and service areas with different customer density. Therefore, an analysis of their cost structure must take account of the fact that the same quantities of electricity can be distributed on differently shaped service areas and that a different quantity of electricity can be distributed on the same service area. For this reason, in the cost model specification we introduce as an explanatory variable the customer density of the service area of a utility. This variable should capture part of the heterogeneity dimension of the distribution process. Unfortunately, the small data set available for this study does not allow us to include in the model specification more service-area characteristic variables such as the number of customers, network length and size of the service area. ${ }^{11}$ For instance, these variables have been introduced in different cost model specifications for electricity distribution utilities. ${ }^{12}$

Output is measured by the total number of $\mathrm{kWh}$ delivered. Inputs to the electricity distribution process consist primarily of labour and capital. The firm's total cost of distributing electricity can then be represented by the cost function

$C=C\left(Y, P_{c}, P_{L}, C D, L F\right)$ 
where $C$ represents total cost and $Y$ is the output represented by the total number of kWh delivered, ${ }^{13}$ and $P_{C}$, and $P_{L}$ are the prices of capital and labour, respectively. $C D$ is the customer density, measured as the ratio between the number of customers and the length of the distribution lines measured in kilometres. ${ }^{14} L F$ is the load factor, which should capture the impact of the intensity of use of the plant on cost. ${ }^{15}$ The variables $C D$ and $L F$ are introduced in the model as output characteristics. The properties of the cost function (4) are that it is concave and linearly homogeneous in input prices and non-decreasing in input prices and output. ${ }^{16}$

The estimation of cost function (4) requires the specification of a functional form. The translog cost function offers an appropriate functional form for answering questions about economies of scale. ${ }^{17}$ However, the small data set available for this study does not allow the use of this functional form, which is characterised by the high number of coefficients to be estimated. Therefore, a log-log functional form was utilised.

$\ln \left(\frac{C}{P_{C}}\right)=\mathrm{a}_{0}+\alpha_{\mathrm{y}} \ln Y+\alpha_{P L} \ln \frac{P_{L}}{P_{C}}+\alpha_{C D} \ln C D+\alpha_{L F} \ln L F$

Note that by normalising total cost and input prices by one of the input prices, we impose the theoretical condition that the cost function is linearly homogeneous in input prices.

\section{Data}

The study is based on the panel data set for five Slovenian electricity distribution utilities over the 1991-2000 period. Data were obtained using utilities' annual reports collected from firms upon request as they have not been published. We could not collect data for earlier periods as the utilities have only been operating as independent companies since 1990 when the divestiture of the vertically integrated electricity company comprising generation, transmission and distribution took place. ${ }^{18}$ As already mentioned, Slovenian electricity distribution utilities operate as local monopolies and therefore operate under quite similar conditions. However, there are still some differences among them in terms of the size of the company, size of the distribution area and the consumer density. The main characteristics of distribution utilities in 2000 are presented in Table 1 . We can see substantial differences in average costs (ranging from $€ 24.70$ to $€ 32.17$ per MWh), labour productivity (ranging from 1,701.03 MWh to 2,697.53 MWh per employee) and capital productivity (ranging from 1,069.05 MWh/MVA to 2,491.32 MWh/MVA). On the other hand, differences regarding the load factor, which measures fluctuations of electricity demand over time, are considerably smaller, ranging from around $60 \%$ to $67 \%$. In 
addition, the share of residential customers (ranging from around $87 \%$ to $90 \%$ ) and the share of sales to households (ranging from around $28 \%$ to $37 \%$ ) are quite similar for all five distribution utilities.

Descriptive statistics of the variables included in the model are presented in Table 2. Following Filippini and Wild (2001), total distribution cost is equal to total expenditures, excluding expenditure for purchased electricity. Average monthly wages are estimated as the labour expenditures divided by the number of employees. ${ }^{19}$ The price of capital is calculated as the ratio of residual capital costs and the capital stock. Residual capital cost is the total distribution cost minus labour cost. The capital stock is approximated by the total installed transformer capacity measured in kVA. All input prices and costs were deflated to 2000 constant Slovenian tolars (SIT) using the producers' price index for electricity, gas and water supply. With exception of the total cost and output, we can see that not much variation is present in the data. 
Table 1 Selected measures for Slovenian distribution utilities in 2000

\begin{tabular}{|c|c|c|c|c|c|}
\hline Utility & 1 & 2 & 3 & 4 & 5 \\
\hline Labour productivity (MWh/employee) & $2,697.53$ & $1,701.03$ & $2,214.46$ & $2,017.52$ & $1,882.83$ \\
\hline Capital productivity (MWh/MVA) & $2,491.32$ & $1,151.91$ & $1,069.05$ & 1,16343 & $1,166.10$ \\
\hline Average cost $(€ / M W h)^{1}$ & 24.70 & 32.17 & 27.10 & 28.06 & 28.82 \\
\hline Customer density 1 (customer/km of network) & 17.48 & 13.04 & 17.50 & 14.23 & 10.50 \\
\hline Customer density 2 (customer $/ \mathrm{km}^{2}$ of area) & 55.86 & 48.72 & 38.11 & 26.64 & 33.28 \\
\hline Load factor ${ }^{3}$ & 0.6738 & 0.5987 & 0.6527 & 0.6528 & 0.6372 \\
\hline Share of household customers (\%) & 89.92 & 89.68 & 88.95 & 86.80 & 89.01 \\
\hline Share of sales to households (\%) & 30.11 & 37.35 & 32.23 & 27.83 & 29.97 \\
\hline
\end{tabular}

${ }^{1}$ Calculated as the ratio of electricity distributed and capital capacity.

${ }^{2}$ Calculations are based on the Bank of Slovenia's official average exchange rate in 2000 of DM (German Mark) $1=$ SIT 104.8310 and $€ 1=$ DM 1.96 .

${ }^{3}$ Load factor represents the relation between average and maximum demand. 


\section{Table 2 Descriptive statistics of variables included in the model}

\begin{tabular}{llrrr}
\hline Variable & Description & 1. Quartile & Median & 3. Quartile \\
\hline$C$ & Total cost (in $€$ thousand) & $31,579.39$ & $44,440.97$ & $65,469.7$ \\
$Y$ & Output (GWh) & 963.54 & $1,374.86$ & $1,576.10$ \\
$P_{L}$ & Price of labour (€/employee) & 742.35 & 808.05 & 890.59 \\
$P_{K}$ & Price of capital (€/kVA) & 15.01 & 17.05 & 20.65 \\
$C D$ & Customer density (customer/km) & 12.93 & 13.74 & 17.50 \\
$L F$ & Load factor & 0.6075 & 0.6226 & 0.6434
\end{tabular}




\section{Empirical analysis}

\section{Estimation results}

The results of the estimation are set out in Table 3. The stochastic cost frontier model has been estimated using a half-normal distribution of the inefficiency and using a programme named Frontier 4.1 by Coelli (1996), which uses a three-step estimation method. In this model, the firm-specific inefficiency term $u_{i}$ is assumed to vary over time.

The estimated function is well behaved. Most of the parameter estimates are highly significant. Since total cost and the regressors are in logarithms, the coefficients are interpretable as cost elasticities. Most of these coefficients have the expected signs and are highly significant. The coefficient of the load factor is, as expected, negative but not significant. This result may be due to the small variation between and within the electricity distribution companies in our sample. The output elasticity is positive and implies that an increase in the production of output will increase total cost. A $1 \%$ increase in the delivery of power will increase total distribution costs by approximately $0.46 \%$.

The cost elasticity with respect to customer density is negative, indicating that a $1 \%$ increase in customer density will reduce costs by approximately $0.60 \%$. This result shows that average distribution costs fall the more densely populated a service area is.

The labour and capital cost shares are positive, implying that the cost function is monotonically increasing in input prices. In the model, labour costs account for approximately $62 \%$ of total electricity distribution costs, while capital accounts for approximately $38 \%$ of total costs. 


\section{Table $3 \quad$ Parameter estimates}

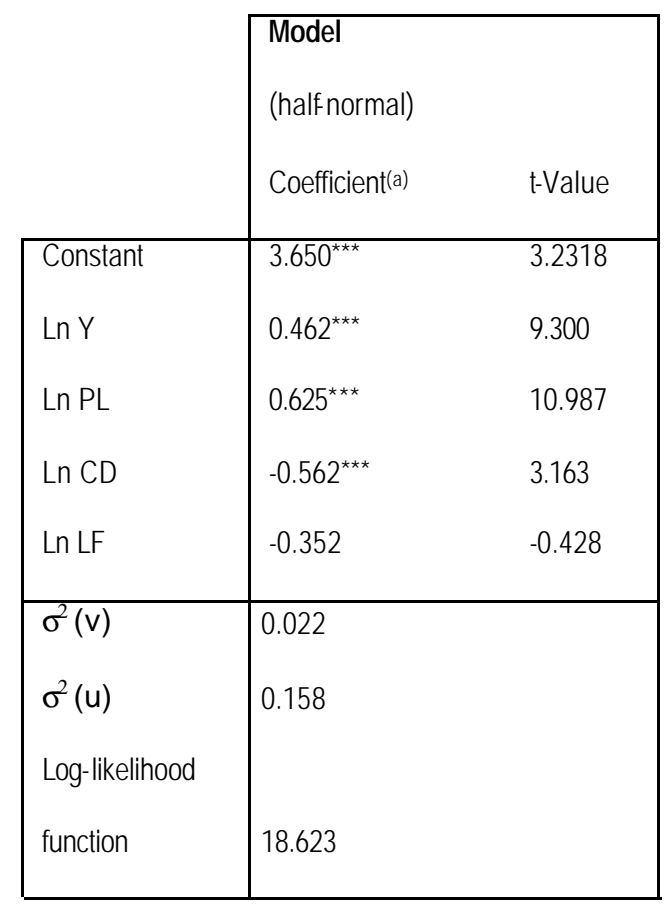

(a) ${ }^{\star * *},{ }^{* *}, *$ : significant at $0.1 \%, 1 \%, 5 \%$, respectively 


\section{Economies of scale}

In the cost model specification (5) we did not separately include the number of customers and the size of the service territory because of a multi-collinearity problem. For this reason, we are unable to introduce, like Roberts (1986) and Filippini (1998), the distinction of economies of output density, economies of customer density and economies of scale. In this study, we define economies of scale $(E S)$ as the proportional increase in total costs brought about by a proportional increase in output, holding all input prices, the load factor, and customer density fixed. This is equivalent to the inverse of the elasticity of total cost with respect to output,

$$
E S=\frac{1}{\frac{\partial \ln C}{\partial \ln Y}}
$$

Economies of scale prevail if $E S$ is greater than 1 and, accordingly, diseconomies of scale exist if $E S$ is below 1 . In the case of $E S=1$ no economies or diseconomies of scale exist. Economies of scale exist if the average costs of an electricity distribution utility decrease as the volume of electricity sold in a service territory of a given customer density increases. We find increasing returns to scale $(E S=2.17)$ for the electricity distribution utilities in our sample.

In Figure 2, the scale expansion path of average costs is shown. Most of the utilities in our sample are, therefore, too small and do not reach the minimum efficient scale. The problem of scale inefficiency might be solved through mergers of small utilities. 
Figure 2 Scale expansion paths of average costs

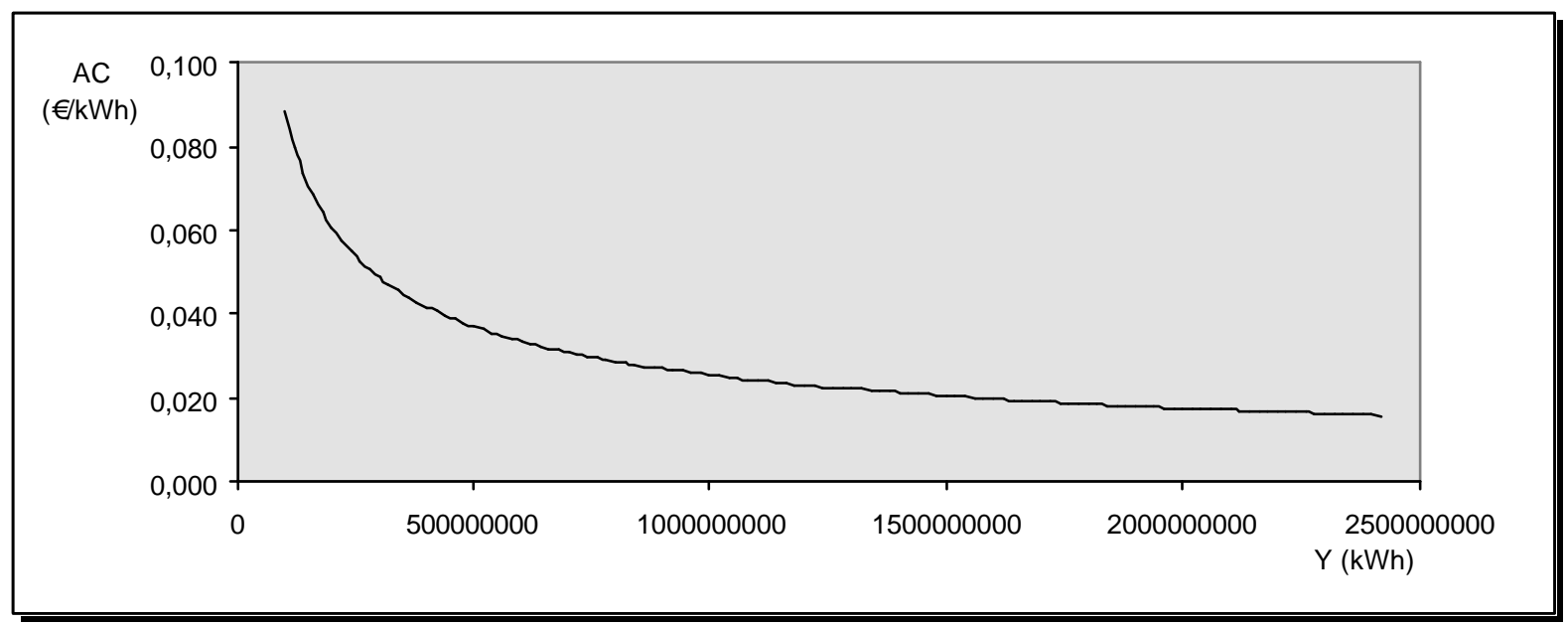




\section{Cost efficiency}

Table 3 can be used to estimate the level of cost inefficiency of each electricity utility along the lines suggested by Simar (1992) and Coelli and Battese (1996). The inefficiency indicator (EFF) can be interpreted as the ratio of actual costs to the efficient level of costs as presented in expression (3). Table 4 shows some summary statistics of efficiency scores (EFF) for the electricity utilities of our sample. ${ }^{20}$

The mean cost inefficiency is about $35 \%$. This value corresponds to the mean cost inefficiency value found by Filippini and Wild (2001) for a sample of Swiss companies. It is worth noting that one electricity distribution company in the sample shows a high degree of inefficiency with a value of 2.25 . Due to the small number of utilities operating in Slovenia, it would be interesting to analyse in more detail the reason for this result. It might be that this company operates in a region characterised by difficult production conditions, which are not taken into account in our model specification. As it was already mentioned, due to the small data set, it was not possible to include more explanatory variables in the model specification. On the other hand, some relevant data on service-area characteristics (e.g. data on geography of the area and prevailing weather conditions) were not available. 
Table 4 Statistics on efficiency scores (EFF)

\begin{tabular}{llll}
\hline & Min & Average & Max \\
\hline EFF Model 1 & 1.04 & 1.35 & 2.25 \\
\hline
\end{tabular}




\section{Conclusion}

In 1999, Slovenia adopted the Energy Law which envisages the introduction of an open electricity market in two stages. In the first stage, running from 15 April 2001 until 2002, the market is opened up to domestic purchases with full market opening envisaged for 2003. Around $64 \%$ of final consumption has been opened to competition. Only households and some low-voltage customers will continue to purchase electricity from distribution companies as they have not been granted eligible customers' rights.

In most countries, deregulation of the electricity industry brings with it the (re)regulation of network access prices. To give network operators efficiency incentives, access price regulation is often implemented with incentive-oriented regulatory instruments such as price-cap regulation or yardstick competition. The new Slovenian law states that network access prices should reflect the costs of an "efficiently operated network company". One way to calculate the costs of an efficient network is to perform a benchmarking analysis and specify the best practice. In this paper, we have applied the stochastic frontier methodology to identify efficient technology.

Based on our findings, we can confirm the presence of increasing returns to scale for Slovenian electricity distribution utilities. Further, we can conclude that most of the utilities in our sample are too small and do not reach the minimum efficient scale. This problem could be solved through mergers of small utilities. Finally, our results suggest that the average cost inefficiency of distribution utilities in our sample is around 35 percent.

\section{References}

Bailey, S J (2002) Public Sector Economics, Second edition, Macmillan, London

Battese, G E (1992), 'Frontier Production Functions and Technical Efficiency: A Survey of Empirical Applications in Agricultural Economics' Agricultural Economics 7 185-208

Battese, G E and Coelli, T J (1992), 'Frontier Production Functions, Technical Efficiency and Panel Data: With Application to Paddy Farmers in India' Journal of Productivity Analysis 3 153-169

Beesley, M E (ed) (1996) Regulating Utilities: A Time for Change, Institute of Economic Affairs (IEA) and London Business School, London 
Bishop, M, Kay, J and Mayer, C (eds) (1995) The Regulatory Challenge, Oxford University Press, Oxford, New York

Coelli, T J (1996) 'A Guide to FRONTIER Version 4.1: A Computer Program for Stochastic Frontier Production and Cost Function Estimation' Mimeo, Department of Econometrics, University of New England, Armidale.

Coelli, T J and Battese, G E (1996) 'Identification of Factors which Influence the Technical Efficiency of Indian Farmers' Australian Journal of Agricultural Economics 40 (2) 19-44

Cornes, R (1992) Duality and Modern Economics, Cambridge University Press

Curwen, P (1994) Privatisation in the UK, The Facts and Figures, Ernst \& Young

Directive 96/92/EC of the European Parliament and of the Council of December 19, 1996 Concerning Common Rules for the Internal Market in Electric ity, OJ L 027, 3.1.1997

Economic Mirror (2002) [Ekonomsko ogledalo, in Slovene] 8 (1)

Energy Law (1999) Ljubljana: Official Journal of the Republic of Slovenia, 79/99

Fabbri, D, Fazioli, R, Filippini, M (1996) L'intervento pubblico e l'efficienza possible, Il Mulino, Bologna

Filippini, M (1996), 'Economies of Scale and Utilization in the Swiss Electric Power Distribution Industry' Applied Economics 28 543-550

Filippini, M (1998) 'Are Municipal Electricity Distribution Utilities Natural Monopolies?' Annals of Public and Cooperative Economics 2 157-174

Filippini, M (1999) 'Cost and Scale Efficiency in the Nursing Home Sector: Evidence from Switzerland' Quaderno N. 99-01, Facoltà di scienze economiche, Università della Svizzera Italiana

Filippini, M and Prioni, P (1994) 'Is Scale and Cost Inefficiency in the Swiss Bus Industry a Regulatory Problem? Evidence from a Frontier Cost Approach' Journal of the Economics of Business 1 (2) 219-31

Filippini, M and Wild, J (2001) 'Regional Differences in Electricity Distribution Costs and their Consequences for Yardstick Regulation of Access Prices' Energy Economics 23 (4) 477-488

Foreman-Peck, J and Waterson, M (1985) 'The comparative efficiency of public and private enterprise in Britain: electricity generation between the world wars' Economic Journal 95 83-95

Helm, D (1994) 'British Utility Regulation: Theory, Practice, and Reform' Oxford Review of Economic Policy 10 (3) $17-40$

Hrovatin, N (1999) 'Industrial Structure and Privatisation of the Slovenian Electricity Industry' Economia delle fonti di energia e dell'ambiente 2 143-183

Hrovatin, N (2001a) 'Restructuring the Slovenian Electricity Industry' Eastern European Economics 39 (5) 6 30

Hrovatin, N (2001b) 'Regulatory Framework for EU Utilities Pricing: Legislation, Enforcement and Institutional Structure’ Working Paper No. 29, Glasgow Caledonian University, May 2001 
Jamasb T, Pollitt M (2000) 'Benchmarking and regulation: international electricity experience' Utilities Policy 9 $107-130$

Jondrow, J, Lowell, C A K , Materov, I S and Schmidt, P (1982) 'On the Estimation of Technical Inefficiency in the Stochastic Frontier Production Function Model' Journal of Econometrics 19 233-238

Joskow, P J and Schmalensee, R (1986) 'Incentive regulation for electric utilities' Yale Journal on Regulation 4 1-49

Kay, J (1996) 'The future of UK Utility Regulation' in Beesley, M E (ed) (1996) Regulating Utilities: A Time for Change, Institute of Economic Affairs (IEA) and London Business School, London, 145-171

McGowan, F and Seabright, P (1995) 'Regulation in the European Community and its Impact on the UK' in Bishop, M, Kay, J and Mayer, C (eds) (1995) The Regulatory Challenge, Oxford University Press, Oxford, New York

Nwankwo, S and Richardson, B (1995) 'The Future of Privatised Utilities (regulation in the UK), in Montanherio L, Nunes R., Owen G, Rebelo E (eds) (1995) Public and Private Sector Partnership in the Global Context, PAVIC Publications, Sheffield, 405-418

Pollitt, M G (1995) Ownership and Performance in Electric Utilities, Oxford University Press, Oxford

Potocnik, J, Senjur M, Štiblar F (eds) (1995) Približevanje Evropi - rast, konkurencnost in integriranje, Strategija gospodarskega razvoja Slovenije [Approaching Europe - Growth, Competitiveness and Integration; Strategy for the Economic Development of Slovenia], Ljubljana, Institute of Macroeconomic Analysis and Development

Price, H E (1996) 'Recent Structural and Regulatory Reforms of the Electricity and Gas Industries in the U.K.' (De)Regulation of Energy: Intersecting Business, Economics and Policy, Conference Proceedings, $17^{\text {th }}$ Annual North American Conference, October 27-30, Boston, Massachusetts, 371-379, United States Association for Energy Economics, International Association for Energy Economics, Cleveland

Rees, R and Vickers, J (1995) 'RPI-X Price-Cap Regulation' in Bishop, M, Kay, J and Mayer, C (eds) (1995) The Regulatory Challenge, Oxford University Press, Oxford, New York, 358-385

Roberts, M J (1986) 'Economies of Density and Size in the Production and Delivery of Electricity' Land Economics 62 (4) 378-387

Robinson, C (1996) 'Profit, Discovery and the Role of Entry: The Case of Electricity' in Beesley M E (ed) (1996) Regulating Utilities: A Time for Change, IEA and London Business School, London, 109-141

Rossi, M A (2001) 'Technical change and efficiency measures: the post-privatisation in the gas distribution sector in Argentina' Energy Economics 23 295-304

Salvanes, K G und Tjøtta, S (1994) 'Productivity Differences in Multiple Output Industries: An Empirical Application to Electricity Distribution' Journal of Productivity Analysis 5 23-43 
Simar, L (1992) 'Estimating Efficiencies from Frontier Models with Panel Data: A Comparison of Parametric, Non-parametric and Semi-parametric Methods with Bootstrapping' The Journal of Productivity Analysis 3 171203

Stelzer, I M (1988) 'Britain’s Newest Import: America's Regulatory Experience’ Oxford Review of Economic Policy 4 (2) 68-79

Stelzer, I M (1996), 'Lessons for UK Regulation from Recent UK Experience' in Beesley M.E. (ed) (1996) Regulating Utilities: A Time for Change, IEA and London Business School, London, 189-203

Thompson, H G (1997) 'Cost Efficiency in Power Procurement and Delivery Service in the Electric Utility Industry’ Land Economics $\mathbf{7 3}$ 287-296

Vickers, J (1996) 'Competition and Regulation: The UK Experience' Beesley, M E (ed) (1996) Regulating Utilities: A Time for Change, Institute of Economic Affairs (IEA) and London Business School, London, 91-105 Walker C D, Lough T (1997) 'A Critical Review of Deregulated Foreign Electric Utility Markets' Energy Policy 25 (10) $877-886$

\section{Notes}

${ }^{1}$ For a general overview of the main benchmarking methods and primary main methods used in the OECD and a few other countries, see Jamasb and Pollit (2000).

${ }^{2}$ For a general discussion of these models, see Joskow and Schmalensee (1986).

${ }^{3}$ Slovenia consumes only half of the electricity generated by the nuclear power plant Krško, since the other half should be exported to neighbouring Croatia due to the plant's joint ownership by the two countries.

${ }^{4}$ A greater ratio of hydropower generation can only be found in Luxembourg (81.8\%), Austria (70.4\%), Sweden (54.7\%) and Portugal (27.7\%) (Economic Mirror, 2002). The hydropower generation level in Slovenia varies as all plants are of the non-accumulated type. The reduced generation (or excess generation) is compensated for by traditional (mostly thermal) power plants. In nuclear power generation, Slovenia stands in third place together with Sweden, after France (76.4\%) in first position and Belgium (56.8\%) in second.

${ }^{5}$ ELES also carried out short-term technical and economic planning, system optimisation, technical relations with the Union for Co-ordination of Production and Transport of Electricity (UCPTE), and electricity trade.

${ }^{6}$ See Hrovatin (2001a) for an analysis of the effects of market opening which would occur without government intervention.

${ }^{7}$ Which price control pattern is better, the USA rate of return or the British price cap, remains a controversial issue. For a discussion on the relative advantages and weaknesses, see for example Stelzer (1988), Stelzer (1996) and for the electricity industry Walker and Lough (1997). Nevertheless, the British RPI-X formula is recognised as being more stimulative for improving efficiency in terms of cost reduction. 


\footnotetext{
${ }^{8}$ In the UK, the real magnitude of information asymmetries became apparent in the case of hostile take-over bid of Trafalgar House for Northern Electric. For more information on this case, see Robinson (1996). Features, problems and results of the UK price cap regulation are discussed by many authors. Some recommendations are Helm (1994), Curwen (1994), Bishop, Kay, Mayer (eds.) (1995), Bailey (1995), Nwankwo - Richardson (1995), Rees - Vickers (1995), McGowan - Seabright (1995), Beesley (ed.) (1996), Kay (1996), Vickers (1996) and Price (1996).

${ }^{9}$ Different approaches can be used to estimate a frontier cost function with panel data. A good overview is given by Battese (1992), Simar (1992) and Fabbri, Fazioli and Filippini (1996). For applications of the stochastic frontier methodology with panel data in Switzerland, see Filippini and Prioni (1994) on the regional bus industry and Filippini (1999).

${ }^{10}$ The inefficiency term $u_{i}$ might also have a time trend (Battese and Coelli, 1992).

${ }^{11}$ Due to a high correlation between these variables and the small number of observations, it was impossible to introduce all these variables in the model specification. To solve this multi-collinearity problem we decided to introduce in the model specification the ratio of two of these variables: the number of customers and the length of the distribution lines.
}

12 See, for example, Roberts (1986), Salvanes and Tj?ota (1994), Thompson (1997), Filippini (1998), Filippini and Wild (2001).

13 See Filippini (1996) for the estimation of a variable cost function for Swiss electricity distribution utilities. However, the model specification of Filippini (1996) does not include area size and the number of customers as explanatory variables.

${ }^{14}$ It could be argued that customer density measured as the ratio between the number of customers and the length of distribution lines is an endogenous variable, since the network length can be more or less efficiently determined by the company. We believe that this is not the case in Slovenia. Due to the fact that electricity distribution companies are public services, customers have to be connected to network by law. The lines are therefore determined by the location of the households. For that reason, the number of customers per km of distribution lines should not be endogeneous variable.

15 See Foreman-Peck and Waterson (1985) for a discussion of the introduction of the load factor into cost models.

${ }^{16}$ See Cornes (1992, p.106).

17 A translog function requires the approximation of the underlying cost function to be made at a local point which in our case is taken at the median point of all variables. Thus, all independent variables are normalised at their median point.

18 Due to this fact we ended up with a small data set imposing limits on the inclusion of more explanatory variables into the model. However, some other studies have also encountered a similar problem. An example is a panel data set of 40 observations included in the estimation of production frontier, the time-varying technical efficiency and the technical change of eight gas distribution regional monopolies in Argentina (Rossi, 2001). 
Since there is a significant lack of empirical studies for the energy sector in Central Eastern European countries we believe that our analysis provides a useful contribution to this area.

${ }^{19}$ Regional differences with respect to wages are not present in Slovenia, since wages in the public sector are determined through collective bargaining on the national level. The average salary varies across companies only because of different age and educational structure of the employees. These differences are taken into account in the study by the inclusion of the average salary in the cost function.

${ }^{20} \mathrm{EFF}$ is calculated as the ratio of actual costs to the efficient level of costs. The values of inefficiency scores can be interpreted as follows: an efficiency score of 1.3292 means that the firm's cost is $32.92 \%$ higher than the cost of an equivalent firm that is efficient. 